Article

\title{
Immune-Enhancement and Anti-Inflammatory Activities of Fatty Acids Extracted from Halocynthia aurantium Tunic in RAW264.7 Cells
}

\author{
Chaiwat Monmai ${ }^{1}$, Seok Hyeon Go ${ }^{1}$, II-Shik Shin ${ }^{1}$, Sang Guan You ${ }^{1}$, Hyungjae Lee ${ }^{2}$ (D), \\ Seok Beom Kang ${ }^{3}$ and Woo Jung Park ${ }^{1, *}$ (D) \\ 1 Department of Marine Food Science and Technology, Gangneung-Wonju National University, \\ Gangneung, Gangwon 25457, Korea; bbuayy@gmail.com (C.M.); gogogo171717@gmail.com (S.H.G.); \\ shinis@gwnu.ac.kr (I.-S.S.); umyousg@gwnu.ac.kr (S.G.Y.) \\ 2 Department of Food Engineering, Dankook University, Cheonan, Chungnam 31116, Korea; \\ lee252@dankook.ac.kr \\ 3 Citrus Research Station, National Institute of Horticultural and Herbal Science, RDA, \\ Seogwipo 63607, Korea; hortkang@korea.kr \\ * Correspondence: pwj0505@gwnu.ac.kr; Tel.: +82-33-640-2857; Fax: +82-33-640-2850
}

Received: 4 July 2018; Accepted: 27 August 2018; Published: 1 September 2018

\begin{abstract}
Halocynthia aurantium, an edible ascidian species, has not been studied scientifically, even though tunicates and ascidians are well-known to contain several unique and biologically active materials. The current study investigated the fatty acid profiles of the H. aurantium tunic and its immune-regulatory effects on RAW264.7 macrophage cells. Results of the fatty acid profile analysis showed a difference in ratios, depending on the fatty acids being analysed, including those of saturated fatty acids (SFA), monounsaturated fatty acids (MUFA), and polyunsaturated fatty acids (PUFA). In particular, omega-3 fatty acids, such as eicosatrienoic acid n-3 (ETA n-3), eicosapentaenoic acid (EPA), and docosahexaenoic acid (DHA), were much higher than omega-6 fatty acids. Moreover, the H. aurantium tunic fatty acids, significantly and dose-dependently, increased the $\mathrm{NO}$ and prostaglandin E2 ( $\left.\mathrm{PGE}_{2}\right)$ production in RAW264.7 cells, for immune-enhancement without cytotoxicity. In addition, these fatty acids regulated the transcription of immune-associated genes, including $i N O S, I L-1 \beta, I L-6, C O X-2$, and TNF- $\alpha$. These actions were activated and deactivated via Mitogen-activated protein kinase (MAPK)and NF- $\mathrm{kB}$ signaling, to regulate the immune responses. Conversely, the $H$. aurantium tunic fatty acids effectively suppressed the inflammatory cytokine expressions, including $i N O S, I L-1 \beta, I L-6, C O X-2$, and TNF- $\alpha$, in LPS-stimulated RAW264.7 cells. Productions of COX-2 and $\mathrm{PGE}_{2}$, which are key biomarkers for inflammation, were also significantly reduced. These results elucidated the immune-enhancement and anti-inflammatory mechanisms of the $H$. aurantium tunic fatty acids in macrophage cells. Moreover, the $H$. aurantium tunic might be a potential fatty acid source for immune-modulation.
\end{abstract}

Keywords: Halocynthia aurantium; tunic; fatty acids; immunomodulation; NF-kB pathway; MAPK

\section{Introduction}

Lipids, including fat-soluble vitamins and fatty acids, are critical nutrients for human health and the prevention of diseases associated with its compositional change [1]. Free fatty acids (FFAs) have been known to be related to immune-modulation [2], and various other fatty acids, such as saturated fatty acids (SFAs), monounsaturated fatty acids (MUFAs), and polyunsaturated fatty acids (PUFAs), are coupled with chronic diseases, including cardiovascular disease [3], cancers [4], and diabetes [5]. 
PUFAs, including omega- 6 and omega- 3 fatty acids, have been known to be associated with inflammation and the immune system [6]. Further, critical fatty acids among PUFAs, which contain more than 20 carbon atoms and more than two double bonds, are arachidonic acid (ARA, 20:4n-6), eicosapentaenoic acid (EPA, 20:5n-3), and docosahexaenoic acid (DHA, 22:6n-3). These play the roles of intermediates for lipid chemicals like eicosanoids and docosanoids, which are important cellular signaling molecules related to inflammation and immune regulation in physiological systems. They are produced by the catalysis of cyclooxygenases (COX) and lipoxygenases (LOX) [7-9]. The precursors of eicosanoids, ARA and EPA, are associated with pro-inflammation and anti-inflammation [10,11], and DHA, which is the precursor of anti-inflammatory docosanoids, such as resolvins and protectins, is a lipid intermediate for cancer therapy. Moreover, EPA, DHA, and long-chain omega-3 PUFA, have been reported to have beneficial effects in diseases, such as arthritis and asthma, through the use of positive immune-regulation [7,9].

Tunicates and ascidians are well-known to contain several unique and biologically active materials, including lipids and lipophilic compounds [12]. One of the sea squirts, Halocynthia roretzi, is known to hold various functional components, such as eicosapentaenoic acid (EPA), docosahexaenoic acid (DHA), carotenoids, taurine, and plasmalogen [13]. The H. roretzi tunics have also been reported to contain high amounts of carotenoid and other nutritious substances [14]. In a report by Konishi [15], acetylene carotenoids, such as alloxanthin and diatoxanthin, which are contained in lipids of $H$. roretzi, suppressed pro-inflammatory cytokine secretions (such as $I L-6$ and $I L-1 \beta$ ) from macrophage-like RAW264.7 cells, that have been stimulated by lipopolysaccharides. It was also reported that halocynthiaxanthin extracted from $H$. roretzi exhibited an anti-proliferative effect on various tumor cells [16].

In contrast, functional fatty acids extracted from Halocynthia aurantium which is an edible ascidian species, have not been studied as much as Halocynthia roretzi, even though H. aurantium is a valuable organism of the benthic marine population in the northern region of the East Sea, Korea [17]. In particular, $H$. aurantium fatty acids have not reported to be associated with immune-regulation, in any scientific study, to date. Therefore, the current study investigated the immunomodulation effects of tunic fatty acids extracted from H. aurantium, on the macrophage cell RAW264.7.

\section{Results}

\subsection{Fatty Acid Analysis of Halocynthia aurantium Tunic}

The total fatty acid compositions from the tunic of sea squirts are shown in Figure 1. The fatty acids were divided into three groups of saturated (SFAs), monounsaturated (MUFA), and polyunsaturated (PUFA) fatty acids. SFAs comprised $53.17 \pm 1.36 \%$, and unsaturated fatty acids, including MUFAs and PUFAs, comprised $12.18 \pm 0.86 \%$ and $34.65 \pm 1.81 \%$, respectively. Among the SFAs, palmitic acid (16:0) and stearidonic acid (18:0) were highest, similar to that of mammals, such as, humans, mice, and other species. Additionally, oleic acid (OA, 18:1) was the highest MUFA, and the tunic contained a much higher proportion of omega-3 PUFAs, such eicosatrienoic acid (ETA, 20:3n-3), EPA and DHA, than omega-6 PUFAs, especially so, for EPA, which was ranked as the highest PUFA.

\subsection{Effect of Fatty Acids from H. aurantium, Tunic Cytotoxicity and NO Production on Macrophages}

To investigate the cytotoxicity of tunic fatty acids extracted from H. aurantium, RAW264.7 cells were cultured with different concentrations of fatty acids. Cellular viability, along with the fatty acids, are shown in Figure 2A, in which tunic fatty acids did not provide any toxicity to RAW264.7 macrophage cells for up to $4 \%$. 


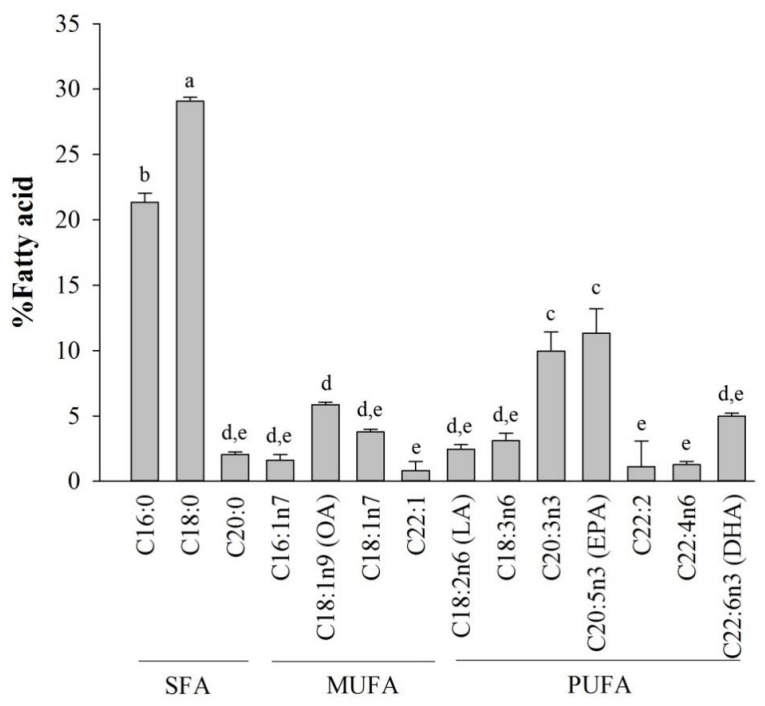

Figure 1. Fatty acid composition of tunic from Halocynthia aurantium. Data are presented as means \pm standard deviation $(n=5)$. The letters $\mathrm{a}, \mathrm{b}, \mathrm{c}, \mathrm{d}$, e indicate a significant difference $(p<0.05)$ between the amount of fatty acid (where, $a>b>c>d>e$ ).

A

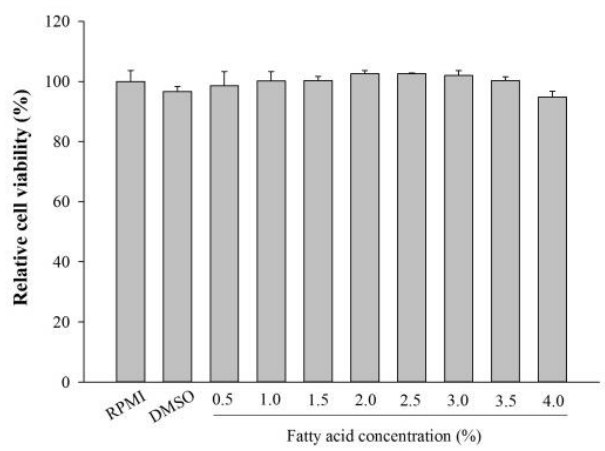

C

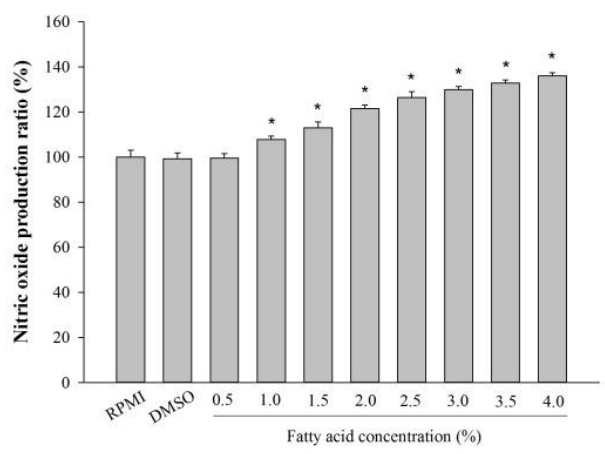

B

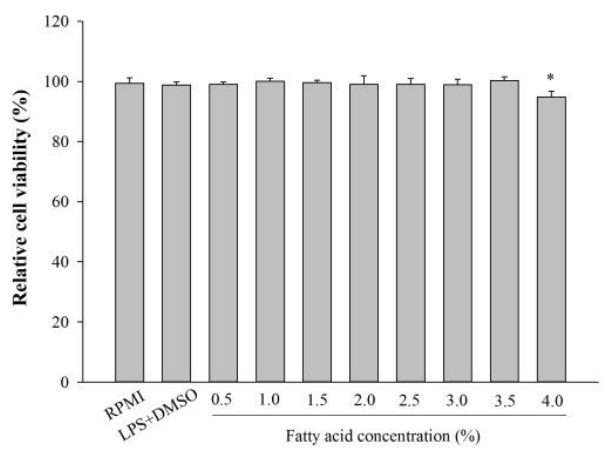

D

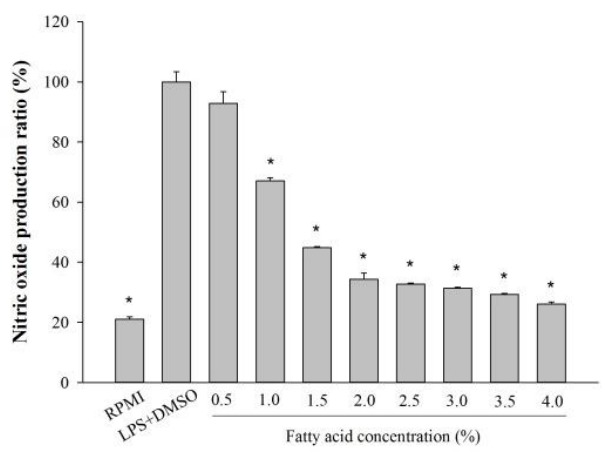

Figure 2. The cytotoxic effect and NO production of fatty acids from the H. aurantium tunic. (A) The cytotoxic effect of $H$. aurantium fatty acids on macrophage proliferation in RAW264.7 cells; (B) The cytotoxic effect of $H$. aurantium fatty acids on macrophage proliferation in LPS-stimulated RAW264.7 cells; (C) The effect of H. aurantium fatty acids on nitric oxide production in RAW264.7 cells; (D) The effect of $H$. aurantium fatty acids on nitric oxide production in LPS-stimulated RAW264.7 cells. RAW264.7 cells were stimulated with or without $1 \mu \mathrm{g} / \mathrm{mL}$ of LPS for $24 \mathrm{~h}$. Significant differences are $p<0.01$, compared with dimethyl sulfoxide (DMSO) or LPS $(*)$. 
In addition, we analyzed the potential immune-stimulation properties and anti-inflammatory effects of fatty acids on RAW264.7 cells when the cells were producing nitric oxide (NO).This is an important factor for pathophysiological conditions, such as inflammation and infection [18]. First, Figure 2B shows that tunic fatty acids enhanced NO production depending on the fatty acid concentrations. Figure $2 \mathrm{C}$ displays the anti-inflammatory activity of fatty acids when lipopolysaccharide (LPS) was used to stimulate inflammation. The results showed that tunic fatty acids significantly inhibited LPS-stimulated NO production depending on the fatty acid concentrations, and NO productions were lowest, and similar, between $2.0-4.0 \%$ fatty acid concentrations.

\subsection{Effect of Fatty Acids from H. aurantium Tunic on Immune Gene Expressions}

Figure 3 shows the immune-regulation of the H. aurantium tunic fatty acids via immune-associated gene expression in RAW264.7 cells. First, gene expressions in RAW264.7 cells increased in a dose-dependent manner, depending on the fatty acid concentration, without any LPS-treatment. Most gene expressions were similarly stimulated by the fatty acids (Figure 3A). However, in LPS-stimulated RAW264.7 cells, the expression of immune-associated genes was dose-dependently inhibited, depending on the fatty acid concentrations (Figure 3B). In particular, the expression of iNOS, one of the key enzymes that can catalyze NO production, was highly reduced by tunic fatty acids, and the expression of other cytokine genes, such as $I L-1 \beta, I L-6$ and COX-2, were also dose-dependently decreased. In addition, the expression of TNF- $\alpha$, another well-known inflammatory biomarker for immune-regulation $[19,20]$, was highly and dose-dependently down-regulated.
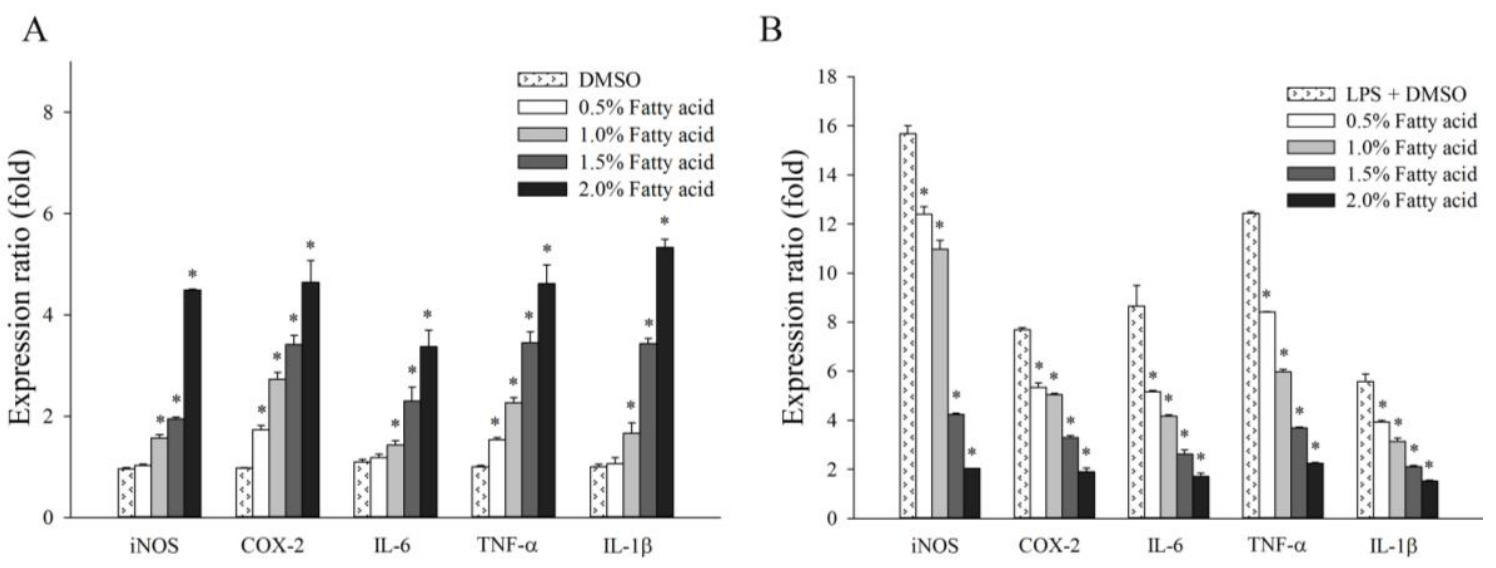

Figure 3. Quantification of immune genes in relative expression (fold). (A) Relative expression of H. aurantium fatty acids in RAW264.7 cells; (B) Relative expression of $H$. aurantium fatty acids in LPS-stimulated RAW264.7 cells. Significant differences are $p<0.01$ compared with DMSO or LPS $\left(^{*}\right)$.

\subsection{Effect of Fatty Acids from H. aurantium Tunic on MAPK and NF-אB Signaling Pathways}

In order to determine the signaling routes by which the $H$. aurantium tunic fatty acids modulate immune-enhancement and anti-inflammation, immune signaling pathways, such as NF-KB and MAPK, were investigated. As shown in Figure 4A,B, H. aurantium tunic fatty acids dose-dependently activated the phosphorylation of NF- $\mathrm{KB}$ p-65 of the NF- $\mathrm{kB}$ signaling pathway, indicating that phosphorylated NF- $\mathrm{KB}$ protein translocated into the nucleus to activate this pathway. Similar to NF- $\mathrm{KB}$ signaling activation, $H$. aurantium tunic fatty acids enhanced the phosphorylation level of MAPK proteins, such Extracellular signal-regulated kinases 1/2 (ERK1/2), c-Jun N-terminal kinase JNK, and p38, in a dose-dependent manner, indicating that MAPK signaling was activated. In contrast, $H$. aurantium tunic fatty acids strongly inhibited NF- $\mathrm{kB}$ p-65 phosphorylation of the NF- $\mathrm{kB}$ signaling pathway under LPS-stimulation in macrophage cells. Moreover, those fatty acids inhibited ERK1/2, JNK, and p38 phosphorylation in a dose-dependent manner in LPS-stimulated RAW264.7 cells (Figure 4C,D). 
These results indicated that $H$. aurantium tunic fatty acids suppressed inflammation in LPS-stimulated macrophage cells through NF- $\mathrm{kB}$ and MAPK signaling routes.

A

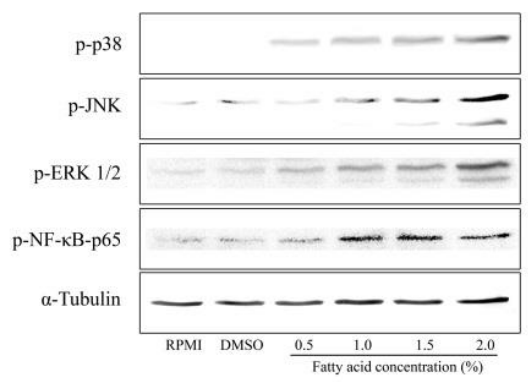

$\mathrm{C}$

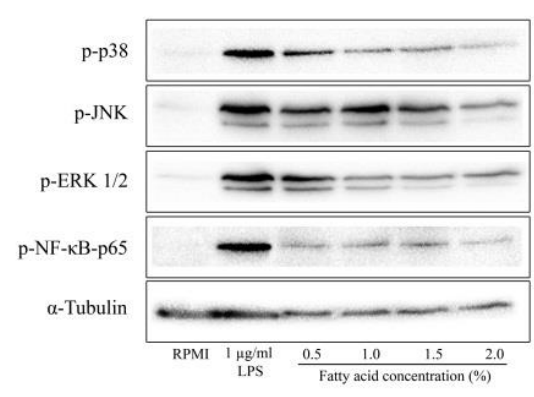

B

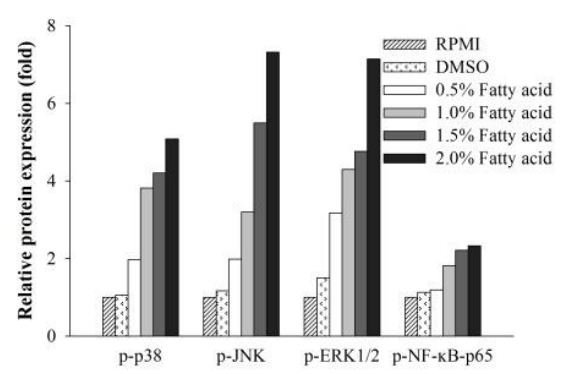

$\mathrm{D}$

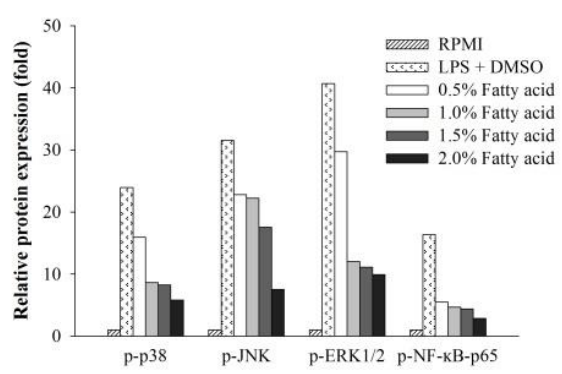

Figure 4. The effect of $H$. aurantium fatty acids on proteins associated with NF-кB and MAPK pathways. (A) Western blot of proteins from RAW264.7 cells; (B) Relative band intensity of proteins from RAW264.7 cells; (C) Western blots of proteins from LPS-stimulated RAW264.7 cells; (D) Relative band intensity of proteins from LPS-stimulated RAW264.7 cells.

\subsection{Effect of Fatty Acids from H. aurantium Tunic on $P G E_{2}$ Levels}

The immunomodulatory and anti-inflammatory effects of $H$. aurantium tunic fatty acids on RAW264.7 cells, were evaluated by the production of $\mathrm{PGE}_{2}$, one of the critical immune biomarkers [21]. Figure $5 \mathrm{~A}$ shows that the production of $\mathrm{PGE}_{2}$ was dose-dependently increased according to the concentration of $H$. aurantium tunic fatty acids. On the contrary, $\mathrm{PGE}_{2}$ production was dose-dependently inhibited, depending on the concentration of $\mathrm{H}$. aurantium tunic fatty acids, in LPS-stimulated RAW264.7 cells (Figure 5B).

A

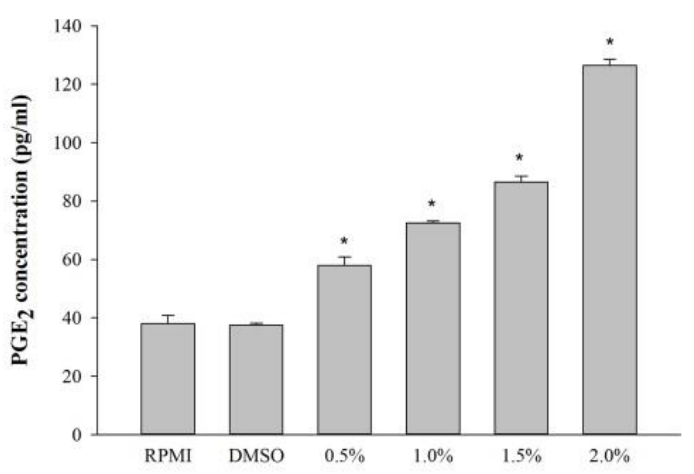

B

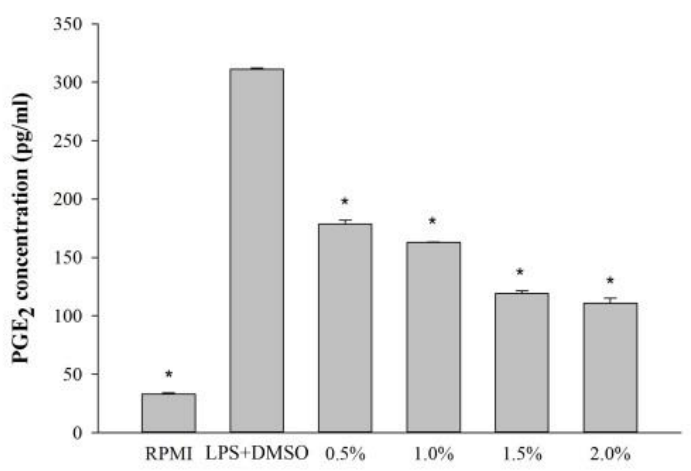

Figure 5. Quantification of $\mathrm{PGE}_{2}$ production from (A) RAW264.7 cells and (B) LPS-stimulated RAW264.7 cells. Significant differences are $p<0.01$ compared with DMSO or LPS $\left(^{*}\right)$. 


\section{Discussion}

Various sea squirts are known to be valuable organisms of the benthic marine population which contains many functional components, including eicosapentaenoic acid (EPA), docosahexaenoic acid (DHA), carotenoids, taurine, and plasmalogen [13]. This current study aimed to investigate the immunomodulatory and anti-inflammatory activities of fatty acids extracted from one of edible sea squirt, $H$. aurantium, on a type of murine macrophage, RAW264.7 cells. The results showed the fatty acid profiles of $H$. aurantium tunic and their effects on immune systems in RAW264.7 cells for immune-stimulation and anti-inflammation.

Among tunic fatty acids, the most abundant fatty acids were SFAs, such as stearic (18:0) and palmitic (16:0), which are similar to the report by Fomenko et al. [22]. It was reported that these SFAs enhanced pro-inflammatory cytokines and immune signaling pathways [23], indicating that SFAs from H. aurantium tunic might play a role in immune-enhancing effects in RAW264.7 cells. Further, PUFAs were much higher than MUFAs, including palmitoleic acid (16:1) and OA, in the H. aurantium tunic and omega- 3 fatty acids, such as ETA, EPA, and DHA, were much higher than omega- 6 fatty acids. Long chain omega-3 fatty acids have beneficial effects on systemic inflammation via disruption of the toll-like receptor (TLR)-signaling cascade and the production of anti-inflammatory eicosanoids, which are mediated by their incorporation into the plasma membrane [24,25]. Furthermore, the action of EPA and DHA on inflammation has been known to affect the phospholipid fatty acid compositional change in the cell membrane, disturbance of lipid rafts, and inactivation of NF- $\mathrm{KB}$, resulting in an alteration of the gene expression associated with immune and fatty acid metabolism [11]. This indicates that the tunic may be an important organ for the use of EPA and DHA, which are precursors for anti-inflammatory eicosanoids and docosanoids and can regulate anti-inflammatory activation [26].

Macrophages are mainly associated with acute and chronic inflammatory responses, which stimulate NO generation, to enhance macrophage functions of killing microorganisms [27]. Therefore, the fatty acids extracted from $H$. aurantium tunic were investigated for immune-stimulation and anti-inflammation using RAW264.7 cells. Figure 2A shows no cytotoxicity of those fatty acids on RAW264.7 cells, suggesting that these are safe at a concentration of up to $4.0 \%$ of fatty acids. In addition, the productions of $\mathrm{NO}$ and $\mathrm{PGE}_{2}$, which are critical immune-regulatory biomarkers for pain, fever, swelling, and tenderness [28], were examined in RAW264.7 cells. The results displayed that $\mathrm{NO}$ and $\mathrm{PGE}_{2}$ were significantly increased according to the fatty acid concentrations (Figures $2 \mathrm{~B}$ and 4A). However, $\mathrm{NO}$ and $\mathrm{PGE}_{2}$ were significantly and dose-dependently decreased in LPS-stimulated RAW264.7 cells (Figures $2 \mathrm{C}$ and $4 \mathrm{~B}$ ). This suggests that the H. aurantium tunic fatty acids not only enhanced the levels of immune biomarkers for immune-enhancement, but they also decreased NO production for anti-inflammation in macrophage cells.

In addition to the production of $\mathrm{NO}$ and $\mathrm{PGE}_{2}$, the expression of immune-associated genes, such as $I L-1 \beta, I L-6$, and TNF- $\alpha$ that are related to inflammation, have been known to regulate immune systems in macrophages [29]. To control immune systems, NF- $k B$ cooperates with inflammatory mediators, such as $i N O S$ and COX-2, and pro-inflammatory cytokines [30]. The activation of NF-kB is stimulated via the phosphorylation and degradation of $\mathrm{I} \kappa \mathrm{B} \alpha$ in order to modulate inflammatory action [31]. Moreover, MAPK, including ERK1/2, JNK, and p38, is crucial for the regulation of cell growth and for cellular differentiation, and is controlled by cellular reactions of immune factors, such as cytokines and stresses [32]. Further, MAPK signaling has been thought to attenuate NF- $\mathrm{KB}$ activation, stimulating the expression of pro-inflammatory cytokines and inflammatory processes [33,34].

The current study showed the expression of immune associated genes, such as $i N O S, I L-1 \beta$, $I L-6$, and TNF- $\alpha$ as well as COX-2, were significantly and dose-dependently increased in RAW non-LPS-treated 264.7 cells (Figure 4A) and decreased in LPS-stimulated RAW264.7 cells (Figure 4B). Varying the gene expressions triggered activation of NF- $\mathrm{KB}$ p-65 and MAPK, including ERK1/2, JNK, and p38. Consequently, the immune responses for both immune-enhancement (Figure 5A,B) and anti-inflammation (Figure $5 \mathrm{C}, \mathrm{D}$ ) were regulated, indicating that $H$. aurantium tunic fatty acids control immune regulation via MAPK as well as NF- $\mathrm{kB}$ signaling activation [35-37]. 


\section{Materials and Methods}

\subsection{Halocynthia aurantium Sample}

One of the sea squirts, H. aurantium, was obtained from the East Sea near Gangwon Province, South Korea. H. aurantium tunic was separated and collected.

\subsection{Fatty Acid Extraction and Analysis}

The extract of total fatty acid from the sea squirt tunic amounted to approximately $3.33 \%$ of the input raw material ( $4.5 \mathrm{~g}$ of raw material: $0.15 \mathrm{~g}$ of fatty acid yield). The extracted fatty acid was dissolved in DMSO to achieve a final concentration of $30 \mathrm{mg} / \mathrm{mL}$ for the immunomodulatory activity assays. Fatty acids were extracted and prepared according to the method of Garces and Mancha [38]. Fatty acid methyl ester (FAMEs) was made by the modified one-step hydrolysis, extraction, and methylation method previously described [39]. Prepared FAMEs from tunic of H. aurantium were analyzed by Gas chromatography (GC)_Flame ionization detection (FID) (Perkin Elmer, Waltham, MA, USA). Eicosanoic acid (20:0) was used as an internal standard in this study.

\subsection{Macrophage Proliferation and Nitric Oxide Production}

Murine macrophages, RAW264.7 cells, in Roswell Park Memorial Institute (RPMI)-1640 medium (supplemented with 10\% Fetal Bovine Serum (FBS) and 1\% penicillin/streptomycin) at a concentration of $1 \times 10^{5}$ cells $/ \mathrm{mL}$ were seeded in a 96-well plate. After $24 \mathrm{~h}$, the different concentrations of tunic fatty acids $(0.5 \%, 1.0 \%, 1.5 \%, 2.0 \%, 2.5 \%, 3.0 \%, 3.5 \%$, or $4.0 \%)$ were injected and incubated for another $24 \mathrm{~h}$. All experiments were carried out in triplicate. EZ-Cytox Cell Viability Assay Kit (Daeil Lab service, Chungcheongbuk, Korea) was used to analyze cellular proliferation, as described by Kim et al. [40]. The cellular proliferation ratio (\%) was calculated based on the following formula:

$$
\text { macrophage proliferation ratio }(\%)=\frac{\text { the absorbance of the test group }}{\text { the absorbance of the control group }} \times 100
$$

Nitric oxide (NO) production was determined to analyze the immunomodulatory activity of fatty acids. Cells were pre-treated, with various concentrations of tunic fatty acids, for $1 \mathrm{~h}$. Anti-inflammation cells were stimulated with LPS (from Escherichia coli O111:B4, Sigma-Aldrich), and immune-enhancement cells were treated without LPS for $24 \mathrm{~h}$. Griess reagent (Sigma-Aldrich, St. Louis, MO, USA) was used for the analysis of the nitric concentration [41].

\subsection{RNA Isolation and cDNA Synthesis}

Total RNA was extracted from cells using the Tri reagent ${ }^{\circledR}$ (Molecular Research Center, Inc., Cincinnati, $\mathrm{OH}, \mathrm{USA}$ ), and the RNA concentration was analyzed using the nanophotometer (Implen, München, Germany). First stand cDNA was synthesized using the High capacity cDNA Reverse Transcription Kit (Applied Biosystems, Waltham, MA, USA), according to the manufacturer's instructions.

\subsection{Expression Analysis of Immune Gene by Real-Time PCR}

Quantification of RAW264.7 immune gene expressions was performed using the QuantStudio ${ }^{\mathrm{TM}}$ 7 Flex Real-Time PCR System (Thermo Fisher Scientific, Waltham, MA, USA) with a 96-well format in a total reaction volume of $20 \mu \mathrm{L} /$ well of SYBR ${ }^{\circledR}$ Premix Ex Taq ${ }^{\mathrm{TM}}$ II (Takara Bio Inc., Shiga, Japan). The reaction mixture consisted of $0.4 \mu \mathrm{M}$ of each specific primer pair (Table 1) and $0.1 \mathrm{ng}$ of cDNA templates. The results were calculated using the $2^{-\Delta \Delta C}$ T method [42] and compared with $\beta$-Actin as a control gene of immune gene expressions. 
Table 1. The sequences of oligonucleotide primers used for macrophage test of immune genes.

\begin{tabular}{cccc}
\hline Gene & Accession No. & Sequence & Product Size (bp) \\
\hline iNOS & BC062378.1 & $\begin{array}{c}\text { F: TTCCAGAATCCCTGGACAAG } \\
\text { R: TGGTCAAACTCTTGGGGTC }\end{array}$ & 180 \\
IL-1 $\beta$ & NM_008361.4 & $\begin{array}{c}\text { F: GGGCCTCAAAGGAAAGAATC } \\
\text { R: TACCAGTTGGGAACTCTGC }\end{array}$ & 183 \\
IL-6 & NM_031168.2 & $\begin{array}{c}\text { F: AGTTGCCTTCTTGGGACTGA } \\
\text { R: CAGAATTGCCATTGCACAAC }\end{array}$ & 191 \\
COX-2 & NM_011198.4 & $\begin{array}{c}\text { F: AGAAGGAAATGGCTGCAGAA } \\
\text { R: GCTCGGCTTCCAGTATTGAG }\end{array}$ & 194 \\
TNF- $\alpha$ & D84199.2 & $\begin{array}{c}\text { F: ATGAGCACAGAAAGCATGATC } \\
\text { R: TACAGGCTTGTCACTCGATT }\end{array}$ & 276 \\
$\beta$-Actin & NM_007393.5 & $\begin{array}{c}\text { R: CCACAGCTGAGAGGAAATC } \\
\text { R: AAGAAGGCTGGAAAAGAGC }\end{array}$ & 193 \\
\hline
\end{tabular}

\subsection{Western Blot Assay}

RAW264.7 cells were harvested with RIPA buffer (Tech \& Innovation, Hebei, China) by stimulation with or without $1 \mu \mathrm{g} / \mathrm{mL}$ of LPS. The protein concentration was measured using the Pierce ${ }^{\mathrm{TM}} \mathrm{BCA}$ Protein Assay Kit (Thermo Scientific, Waltham, MA, USA). After separation by SDS-polyacrylamide gel electrophoresis (SDS-PAGE), the proteins were transferred to a polyvinylidene fluoride (PVDF) membrane, and the western blot assay was performed as described by Narayanan et al. [43]. Specific antibodies were used for p-NF- $\mathrm{kB}$ p65 (Cell Signaling Technology), p-p38 (Cell Signaling Technology), p-ERK1/2 (Cell Signaling Technology), p-JNK (Cell Signaling Technology), and $\alpha$-Tubulin (Abcam). Signals were recognized using the Pierce ${ }^{\circledR}$ ECL Plus Western Blotting Substrate (Thermo Scientific, Waltham, MA, USA) and the blot was quantitated using the ChemiDoc XRS+ imaging system (Bio-Rad) and ImageLab software (version 4.1, Bio-Rad, Hercules, CA, USA).

\subsection{Quantification of $P G E_{2}$}

$\mathrm{PGE}_{2}$ ELISA kit (Enzo Life Sciences, Farmingdale, NY, USA) was used to analyze $\mathrm{PGE}_{2}$ according to the manufacturer's instructions. The analysis was performed in duplicate, and the quantification of $\mathrm{PGE}_{2}$ in the samples was evaluated based on a standard curve.

\subsection{Statistics}

'Statistix (version 8.1)' Statistics Software, Statistix, Tallahassee, FL, USA) was used for the statistical analysis, and the values were evaluated by one-way analysis of variance, followed by post-hoc Duncan's multiple range tests. The differences between the two groups were compared using t-tests $(p<0.05)$. The results of fatty acid analyses are shown as means \pm standard deviation. Differences between each fatty acid were examined for statistical significance using one-way analysis of variance, followed by Tukey's pair-wise comparisons at $p<0.05$.

\section{Conclusions}

Our study demonstrated the immune-enhancement as well as the anti-inflammatory regulation of $H$. aurantium tunic fatty acids (consisting of SFA, MUFA, and PUFA) in RAW264.7 cells. This is evident from the diverse biological results that could be observed, such as, alterations of the key, immune biomarkers like $\mathrm{NO}$ and $\mathrm{PGE}_{2}$, immune-associated gene expression, and, the MAPK and NF- $\mathrm{KB}$ signaling for regulating immune responses. These results might be helpful to understand the regulatory roles of $H$. aurantium tunic fatty acids, consisting of SFA, MUFA, and PUFA, on immune cells. Moreover, the results suggest that $H$. aurantium tunic has a potential fatty acid source which could be used for immune-modulation. 
Author Contributions: C.M. designed and performed the experiments, analyzed data, and wrote the manuscript. S.H.G. performed the experiments. I.-S.S., S.G.Y., H.L. and S.B.K. edited the manuscript. W.J.P. designed the experiment, analyzed data, and wrote the manuscript.

Funding: This research project is supported by the University Emphasis Research Institute Support Program (No.2018R1A61A03023584) from the National Research Foundation of Korea and the Basic Science Research Program through the National Research Foundation of Korea (NRF) funded by the Ministry of Science, ICT \& Future Planning (2016R1A2B4011743).

Conflicts of Interest: The authors declare no conflicts of interest.

\section{References}

1. Roche, H.M. Unsaturated fatty acids. Proc. Nutr. Soc. 1999, 58, 397-401. [CrossRef] [PubMed]

2. Walls, J.; Sinclair, L.; Finlay, D. Nutrient sensing, signal transduction and immune responses. Semin. Immunol. 2016, 28, 396-407. [CrossRef] [PubMed]

3. Superko, H.R.; Superko, A.R.; Lundberg, G.P.; Margolis, B.; Garrett, B.C.; Nasir, K.; Agatston, A.S. Omega-3 fatty acid blood levels clinical significance update. Curr. Cardiovasc. Risk Rep. 2014, 8, 407-414. [CrossRef] [PubMed]

4. Ford, J.H. Saturated fatty acid metabolism is key link between cell division, cancer, and senescence in cellular and whole organism aging. Age (Dordr) 2010, 32, 231-237. [CrossRef] [PubMed]

5. Zheng, J.S.; Huang, T.; Yang, J.; Fu, Y.Q.; Li, D. Marine N-3 polyunsaturated fatty acids are inversely associated with risk of type 2 diabetes in Asians: A systematic review and meta-analysis. PLoS ONE 2012, 7, e44525. [CrossRef] [PubMed]

6. Simopoulos, A.P. Omega-3 fatty acids in inflammation and autoimmune diseases. J. Am. Coll. Nutr. 2002, 21, 495-505. [CrossRef] [PubMed]

7. Calder, P.C. Omega-3 polyunsaturated fatty acids and inflammatory processes: Nutrition or pharmacology? Br. J. Clin. Pharmacol. 2013, 75, 645-662. [CrossRef] [PubMed]

8. Davidson, J.; Rotondo, D.; Rizzo, M.T.; Leaver, H.A. Therapeutic implications of disorders of cell death signalling: Membranes, micro-environment, and eicosanoid and docosanoid metabolism. Br. J. Pharmacol. 2012, 166, 1193-1210. [CrossRef] [PubMed]

9. Wolfe, L.S. Eicosanoids: Prostaglandins, thromboxanes, leukotrienes, and other derivatives of carbon-20 unsaturated fatty acids. J. Neurochem. 1982, 38, 1-14. [CrossRef] [PubMed]

10. Adam, O.; Beringer, C.; Kless, T.; Lemmen, C.; Adam, A.; Wiseman, M.; Adam, P.; Klimmek, R.; Forth, W. Anti-inflammatory effects of a low arachidonic acid diet and fish oil in patients with rheumatoid arthritis. Rheumatol. Int. 2003, 23, 27-36. [CrossRef] [PubMed]

11. Calder, P.C. Omega-3 fatty acids and inflammatory processes: From molecules to man. Biochem. Soc. Trans. 2017, 45, 1105-1115. [CrossRef] [PubMed]

12. Dagorn, F.; Dumay, J.; Wielgosz-Collin, G.; Rabesaotra, V.; Viau, M.; Monniot, C.; Biard, J.F.; Barnathan, G. Phospholipid distribution and phospholipid fatty acids of the tropical tunicates Eudistoma sp. and Leptoclinides uniorbis. Lipids 2010, 45, 253-261. [CrossRef] [PubMed]

13. Mikami, N.; Hosokawa, M.; Miyashita, K. Effects of sea squirt (Halocynthia roretzi) lipids on white adipose tissue weight and blood glucose in diabetic/obese KK-Ay mice. Mol. Med. Rep. 2010, 3, 449-453. [CrossRef] [PubMed]

14. Rohmah, Z.; Jeong, U.C.; Ticar, B.F.; Kim, J.-S.; Lee, J.-J.; Kang, S.J.; Choi, B.D. Effect of ascidian (Halocynthia roretzi, Drasche 1884) tunics carotenoids on enhancing growth and muscle coloring of sea-reared rainbow trout (Oncorhynchus mykiss, Walbaum 1792). Aquacult. Rep. 2016, 4, 22-29. [CrossRef]

15. Konishi, I.; Hosokawa, M.; Sashima, T.; Maoka, T.; Miyashita, K. Suppressive effects of alloxanthin and diatoxanthin from Halocynthia roretzi on LPS-induced expression of pro-inflammatory genes in RAW264.7 cells. J. Oleo Sci. 2008, 57, 181-189. [CrossRef] [PubMed]

16. Nishino, H.; Tsushima, M.; Matsuno, T.; Tanaka, Y.; Okuzumi, J.; Murakoshi, M.; Satomi, Y.; Takayasu, J.; Tokuda, H.; Nishino, A.; et al. Anti-neoplastic effect of halocynthiaxanthin, a metabolite of fucoxanthin. Anticancer Drugs 1992, 3, 493-497. [CrossRef] [PubMed]

17. Lee, C.; Park, M.W.; Lee, C.S.; Kim, S.K.; Kim, W.K. Effects of temperature and salinity on development of sea peach Halocynthia aurantium. J. Environ. Sci. 2009, 18, 1171-1179. [CrossRef] 
18. Lechner, M.; Lirk, P.; Rieder, J. Inducible nitric oxide synthase (iNOS) in tumor biology: The two sides of the same coin. Semin. Cancer Biol. 2005, 15, 277-289. [CrossRef] [PubMed]

19. Baugh, J.A.; Bucala, R. Mechanisms for modulating TNF alpha in immune and inflammatory disease. Curr. Opin. Drug Discov. Devel. 2001, 4, 635-650. [PubMed]

20. Popa, C.; Netea, M.G.; van Riel, P.L.; van der Meer, J.W.; Stalenhoef, A.F. The role of TNF-alpha in chronic inflammatory conditions, intermediary metabolism, and cardiovascular risk. J. Lipid Res. 2007, 48, 751-762. [CrossRef] [PubMed]

21. Meirow, Y.; Baniyash, M. Immune biomarkers for chronic inflammation related complications in non-cancerous and cancerous diseases. Cancer Immunol. Immunother. 2017, 66, 1089-1101. [CrossRef] [PubMed]

22. Fomenko, S.E.; Kushnerova, N.F.; Lesnikova, L.N. Experimental assessment of the efficiency of erythrocyte membrane repair by an extract of the tunic of the ascidian purple sea squirt in carbon tetrachloride poisoning. Pharm. Chem. J. 2013, 46, 606-611. [CrossRef]

23. Yang, X.; Haghiac, M.; Glazebrook, P.; Minium, J.; Catalano, P.M.; Hauguel-de Mouzon, S. Saturated fatty acids enhance TLR4 immune pathways in human trophoblasts. Hum. Reprod. 2015, 30, 2152-2159. [CrossRef] [PubMed]

24. De Pablo Manuel, A.; De Cienfuegos Gerardo, Á. Modulatory effects of dietary lipids on immune system functions. Immunol. Cell Biol. 2000, 78, 31-39. [CrossRef] [PubMed]

25. Guertin, M.H.; Robitaille, K.; Pelletier, J.F.; Duchesne, T.; Julien, P.; Savard, J.; Bairati, I.; Fradet, V. Effects of concentrated long-chain omega-3 polyunsaturated fatty acid supplementation before radical prostatectomy on prostate cancer proliferation, inflammation, and quality of life: Study protocol for a phase IIb, randomized, double-blind, placebo-controlled trial. BMC Cancer 2018, 18, 64-73. [CrossRef] [PubMed]

26. Lee, J.M.; Lee, H.J.; Kang, S.B.; Park, W.J. Fatty acid desaturases, polyunsaturated fatty acid regulation, and biotechnological advances. Nutrients 2016, 8, 23. [CrossRef] [PubMed]

27. Olefsky, J.M.; Glass, C.K. Macrophages, inflammation, and insulin resistance. Annu. Rev. Physiol. 2010, 72, 219-246. [CrossRef] [PubMed]

28. Hu, S.S.; Bradshaw, H.B.; Chen, J.S.; Tan, B.; Walker, J.M. Prostaglandin $E_{2}$ glycerol ester, an endogenous COX-2 metabolite of 2-arachidonoylglycerol, induces hyperalgesia and modulates NFKB activity. Br. J. Pharmacol. 2008, 153, 1538-1549. [CrossRef] [PubMed]

29. Zhao, Y.; Liu, J.; Liu, C.; Zeng, X.; Li, X.; Zhao, J. Anti-inflammatory effects of p-coumaric acid in LPS-stimulated RAW264.7 cells: Involvement of NF-kB and MAPKs pathways. J. Med. Chem. 2016, 6, 327-330. [CrossRef]

30. Tak, P.P.; Firestein, G.S. NF-кB: A key role in inflammatory diseases. J. Clin. Investig. 2001, 107, 7-11. [CrossRef] [PubMed]

31. Baeuerle, P.A.; Baltimore, D. NF-kB: Ten years after. Cell 1996, 87, 13-20. [CrossRef]

32. Kim, J.B.; Han, A.R.; Park, E.Y.; Kim, J.Y.; Cho, W.; Lee, J.; Seo, E.K.; Lee, K.T. Inhibition of LPS-induced iNOS, COX-2 and cytokines expression by poncirin through the NF-kappaB inactivation in RAW 264.7 macrophage cells. Biol. Pharm. Bull. 2007, 30, 2345-2351. [CrossRef] [PubMed]

33. Cargnello, M.; Roux, P.P. Activation and function of the MAPKs and their substrates, the MAPK-activated protein kinases. Microbiol. Mol. Biol. Rev. 2011, 75, 50-83. [CrossRef] [PubMed]

34. Li, Y.Y.; Hsieh, L.L.; Tang, R.P.; Liao, S.K.; Yeh, K.Y. Interleukin-6 (IL-6) released by macrophages induces IL-6 secretion in the human colon cancer HT-29 cell line. Hum. Immunol. 2009, 70, 151-158. [CrossRef] [PubMed]

35. Han, L.; Song, S.; Niu, Y.; Meng, M.; Wang, C. Eicosapentaenoic acid (EPA) induced macrophages activation through GPR120-mediated Raf-ERK1/2-IKK $\beta-N F-\kappa B ~ p 65$ signaling pathways. Nutrients 2017, 9, 937. [CrossRef] [PubMed]

36. Novak, T.E.; Babcock, T.A.; Jho, D.H.; Helton, W.S.; Espat, N.J. NF-кB inhibition by omega-3 fatty acids modulates LPS-stimulated macrophage TNF-alpha transcription. Am. J. Physiol. 2003, 284, L84-L89. [CrossRef]

37. Zhao, Y.; Joshi-Barve, S.; Barve, S.; Chen, L.H. Eicosapentaenoic acid prevents LPS-induced TNF- $\alpha$ expression by preventing NF-кB activation. J. Am. Coll. Nutr. 2004, 23, 71-78. [CrossRef] [PubMed]

38. Garces, R.; Mancha, M. One-step lipid extraction and fatty acid methyl esters preparation from fresh plant tissues. Anal. Biochem. 1993, 211, 139-143. [CrossRef] [PubMed] 
39. Park, W.J.; Kothapalli, K.S.; Lawrence, P.; Tyburczy, C.; Brenna, J.T. An alternate pathway to long-chain polyunsaturates: The $F A D S_{2}$ gene product $\triangle 8$-desaturates 20:2n-6 and 20:3n-3. J. Lipid Res. 2009, 50, 1195-1202. [CrossRef] [PubMed]

40. Kim, J.K.; Cho, M.L.; Karnjanapratum, S.; Shin, I.S.; You, S.G. In vitro and in vivo immunomodulatory activity of sulfated polysaccharides from Enteromorpha prolifera. Int. J. Biol. Macromol. 2011, 49, 1051-1058. [CrossRef] [PubMed]

41. Cao, R.A.; Lee, Y.; You, S.G. Water soluble sulfated-fucans with immune-enhancing properties from Ecklonia cava. Int. J. Biol. Macromol. 2014, 67, 303-311. [CrossRef] [PubMed]

42. Livak, K.J.; Schmittgen, T.D. Analysis of relative gene expression data using real-time quantitative PCR and the $2^{-\Delta \Delta C}$ T Method. Methods 2001, 25, 402-408. [CrossRef] [PubMed]

43. Narayanan, B.A.; Narayanan, N.K.; Simi, B.; Reddy, B.S. Modulation of inducible nitric oxide synthase and related proinflammatory genes by the omega-3 fatty acid docosahexaenoic acid in human colon cancer cells. Cancer Res. 2003, 63, 972-979. [PubMed]

(c) 2018 by the authors. Licensee MDPI, Basel, Switzerland. This article is an open access article distributed under the terms and conditions of the Creative Commons Attribution (CC BY) license (http:/ / creativecommons.org/licenses/by/4.0/). 